\title{
Individual Pharmacotherapy Management (IPM) - I: a group-matched retrospective controlled clinical study on prevention of complicating delirium in the elderly trauma patients and identification of associated factors
}

\author{
Luise Drewas ${ }^{1,2}$, Hassan Ghadir ${ }^{1,3}$, Rüdiger Neef ${ }^{4}$, Karl-Stefan Delank $^{5}$ and Ursula Wolf $f^{*}$
}

\begin{abstract}
Background: Delirium is one of the most frequent complications in hospitalized elderly patients with additional costs such as prolongation of hospital stays and institutionalization, with risk of reduced functional recovery, longterm cognitive impairment, and increased morbidity and mortality. We analyzed the effect of individual pharmacotherapy management (IPM) in the University Hospital Halle in geriatric trauma patients on complicating delirium and aimed to identify associated factors.

Methods: In a retrospective controlled clinical study of 404 hospitalized trauma patients $\geq 70$ years we compared the IPM intervention group (IG) with a control group (CG) before IPM implementation. Delirium was recorded from the hospital discharge letter. The medication review and data records included baseline data, all medications, diagnoses, electrocardiogram (ECG), laboratory and vital parameters during hospitalization. The IPM internist and the senior trauma physician guaranteed personnel and structural continuity in the implementation of the interdisciplinary patient rounds.

Results: There was a highly matched congruence between CG and IG in terms of age, gender, residency, BMI, most diagnoses, and injury patterns to compare the two groups. The total number of medications per patient was $11.1 \pm 4.9$ (CG) versus 10.4 \pm 3.6 (IG). Our targeted IPM focus on 6 frontline aspects with reduction of antipsychotics, anticholinergic burden, benzodiazepines, serotonergic opioids, elimination of pharmacokinetic and pharmacodynamic drug interactions and overdosage reduced complicating delirium from $5 \%$ to almost zero at $0.5 \%$. The association of IPM with a significant 10-fold reduction, $\mathrm{OR}=0.09$ [95\% $\mathrm{Cl} 0.01-0.7]$, in univariable regression, maintained of clinical relevance in multivariable regression $\mathrm{OR}=0.1$ [95\% $\mathrm{Cl} 0.01-1.1]$. Factors most strongly associated with complicating delirium in univariable regression were cognitive dysfunction, nursing home residency, muscle relaxants, antiparkinsonian agents, xanthines, transient disorientation documented in the fall risk scale, antibiotic-requiring infections, antifungals, antipsychotics, and intensive care stay, the two latter maintaining significance in multivariable regression.
\end{abstract}

\footnotetext{
*Correspondence: ursula.wolf@uk-halle.de

1 Pharmacotherapy Management Department, University Hospital Halle

(Saale), Ernst-Grube-Straße 40, 06120 Halle (Saale), Germany

Full list of author information is available at the end of the article
} original author(s) and the source, provide a link to the Creative Commons licence, and indicate if changes were made. The images or other third party material in this article are included in the article's Creative Commons licence, unless indicated otherwise in a credit line to the material. If material is not included in the article's Creative Commons licence and your intended use is not permitted by statutory regulation or exceeds the permitted use, you will need to obtain permission directly from the copyright holder. To view a copy of this licence, visit http://creativecommons.org/licenses/by/4.0/. The Creative Commons Public Domain Dedication waiver (http://creativeco mmons.org/publicdomain/zero/1.0/) applies to the data made available in this article, unless otherwise stated in a credit line to the data. 
Conclusions: IPM is associated with a highly effective prevention of complicating delirium in the elderly trauma patients. For patient safety it should be integrated as an essential preventative contribution. The associated factors help identify patients at risk.

Keywords: Delirium, Elderly patients, Traumatology, Prevention, Polypharmacy, Medication review, Risk factors, Adverse drug reactions, Serotonin syndrome, ICD-classification

\section{Background}

Delirium occurs in the general population with a prevalence of $1-2 \%$ [1]. However, it is found in $10-15 \%$ of elderly patients presenting to the emergency department [1], and delirium is one of the most frequent and feared complications in elderly patients during hospitalization $[2,3]$. It causes significant additional economic and social costs such as prolongation of hospital stay by an average of 8 days, reduced functional recovery, long-term decline in cognitive performance, and increased morbidity and mortality [1-4]. Symptoms of delirium persist in one-third of patients, which is associated with a generally worse prognosis for patients $[2,5]$. Delirium has therefore become an increasing focus of research and everyday life in recent years.

Delirium is considered to have a multifactorial genesis [1].

$90 \%$ of patients $>65$ years of age regularly take prescription medications. Of these, approximately $20-50 \%$ have an anticholinergic side effect profile [6]. In 12-39\% of cases, medications were the sole determining cause for the development of delirium [7]. Polypharmacy, described in the metadata analysis by Masnoon et al. [8] as permanent use of at least 5 medications, increases the incidence of delirium by a factor of 4.5 in the elderly population $[1,9]$. The most common drugs associated with delirium were benzodiazepines, opioids, and preparations with anticholinergic side effects such as antiemetics, spasmolytics, antiarrhythmics, antihistamines, corticosteroids, muscle relaxants, and psychotropic agents $[1,7]$.

Elderly patients are additionally more susceptible to adverse drug reactions (ADR). The blood-brain barrier becomes more permeable with age, and the renal and hepatic filtering and metabolizing processes deteriorate $[10,11]$. Damage to the blood-brain barrier by postoperative inflammatory processes [12] with an increase in inflammatory parameters such as Interleucin-6 and Interleucin- 8 is discussed as a further cause of delirium $[13,14]$.

Another increase in the incidence of delirium is seen in acute inpatient admissions and traumatology surgical treatments. For example, the incidence of delirium in patients undergoing orthopedic and trauma surgical treatment ranges from 12 to $51 \%$ according to US data [1]. These figures are consistent with intervention studies from Germany. Here, 20.2-20.8\% of >70-yearold patients developed delirium after general surgical care [15]. In 2008, Robinson et al. compared the delirium incidences of different surgical procedures and concluded that the degree of surgical exposure was related to the development of delirium. They found that cataract surgery caused only low levels of surgical stress, as the incidence of delirium was $4 \%$, whereas high-risk surgeries, such as vascular procedures, had an incidence of $36 \%$ [16].

In the decades-long efforts to explain delirium, it was initially regarded as an agitation disorder with alteration of consciousness, i.e., as a mere mental state problem [1]. A clear terminology was lacking.

Z. J. Lipowski described this problem as "semantic confusion" in 1983. He postulated that scientific work in the field of delirium was hindered by the lack of a clear definition and the absence of precise diagnostic criteria [17]. At that time, "acute state of confusion", "senile delirium", "acute brain syndrome" or "pseudosenility", among others, were used in parallel. Lipowski first proposed to use the term "delirium" exclusively for transient, global cognitive disorders, joining the Diagnostic and Statistical Manual of Mental Disorders of the American Psychiatric Association (DSM)-III classification system updated in 1980 [17].

This work was the first to distinguish between "hyperactive" and "hypoactive" delirium [18]. Since then, 4 motor subtypes have been described. Common to all 4 subtypes are altered sleep-wake rhythms, disturbances in attention and memory, alterations in thinking and speech, and perceptual disturbances $[19,20]$.

The American DSM-5 currently describes delirium as a fluctuating disorder of attention and consciousness that develops acutely over hours to a few days. In addition, there is an alteration of cognition (disorientation, memory deficit, disturbances in perceptual ability). These disturbances cannot be explained by neurocognitive disorders, such as dementia. Instead, there is evidence from the medical history or from clinical examinations that this disorder is a direct consequence of a medical condition, intoxication, or withdrawal [21]. This is inconsistent with the current International Classification of Diseases (ICD)-10 classification of delirium. There, in its main heading it is described as an "aetiologically non-specific 
brain-organic syndrome not caused by alcohol or other psychotropic substances, characterized by simultaneous disturbances of consciousness on the one hand and at least two of the following disturbances on the other: disturbances of attention, perception, thinking, memory, psychomotor function, emotionality or sleep-wake rhythm. The duration varies greatly [...]" [22].

The aim of the present study was to investigate the intervention effect of individual pharmacotherapy management (IPM) in trauma geriatric patients with subsequent medication adjustment on the incidence of complicating delirium and to identify predisposing associated factors. The hypothesis is that because some are medication-induced, a certain proportion is preventable by targeted clinical pharmacological intervention in perioperative medication.

\section{Methods}

\section{Study design, patient population and setting}

To investigate the effects of IPM on delirium, we conducted a retrospective controlled clinical study enrolling 404 inpatients $\geq 70$ years of age from the Department of Trauma and Reconstructive Surgery for a two-arm evaluation: 204 patients with IPM intervention from the IPM period and 200 patients without IPM from the period before IPM implementation. Completion of random recruitment, blinded for the outcome complicating delirium, provided two inpatient samples that showed group-matching for age, gender, residency, BMI, most diagnoses, and injury patterns, which were thus excluded as important potential confounders of delirium manifestation (Fig. 1).

IPM for inpatients $\geq 70$ years of age at the Department of Trauma Surgery at the University Hospital Halle
(Saale) (UKH) started in February 2011 with the implementation of an interdisciplinary fortnightly ward rounds on the traumatology ward in addition to individual medication reviews. Uniformity of patient rounds was ensured by the continuous presence of the same responsible internal medicine/pharmacotherapy management specialist with the same senior geriatric traumatology physician, accompanied by residents and geriatricians, medical students, and nurses. From the intervention period, 204 patients $\geq 70$ years of age (intervention group, IG) were enrolled with samples from May 2012 to August 2016. The control group (CG) included 200 patients $\geq 70$ years of age who were hospitalized in the same ward between February 2009 and December 2010. Because outcomes had already occurred at the time of recruitment, both cohorts included samples that were blinded to outcome. In the Department of Trauma Surgery, the total number of geriatric patients aged $\geq 70$ years admitted as inpatients in the years of recruitment was: 335 patients in 2009 and 459 patients in 2010, 433 patients in 2012, 477 in 2013, 471 in 2014, 428 in 2015, and 431 in 2016. Recruitment of patients in the intervention group over the years was intended to assess lasting and stable potential effects. The patient recruitment in each group and from the different years was at random and performed individually for each group. The final group population was a matched one comparing control and intervention group with respect to age, gender, residency, BMI, most diagnoses, and injury patterns. This group-match resulted by chance and it was not proactively controlled in either group during the recruitment phase. For the conductance and the interpretation of the study results, the agreement of the groups with respect to relevant confounders is one of the

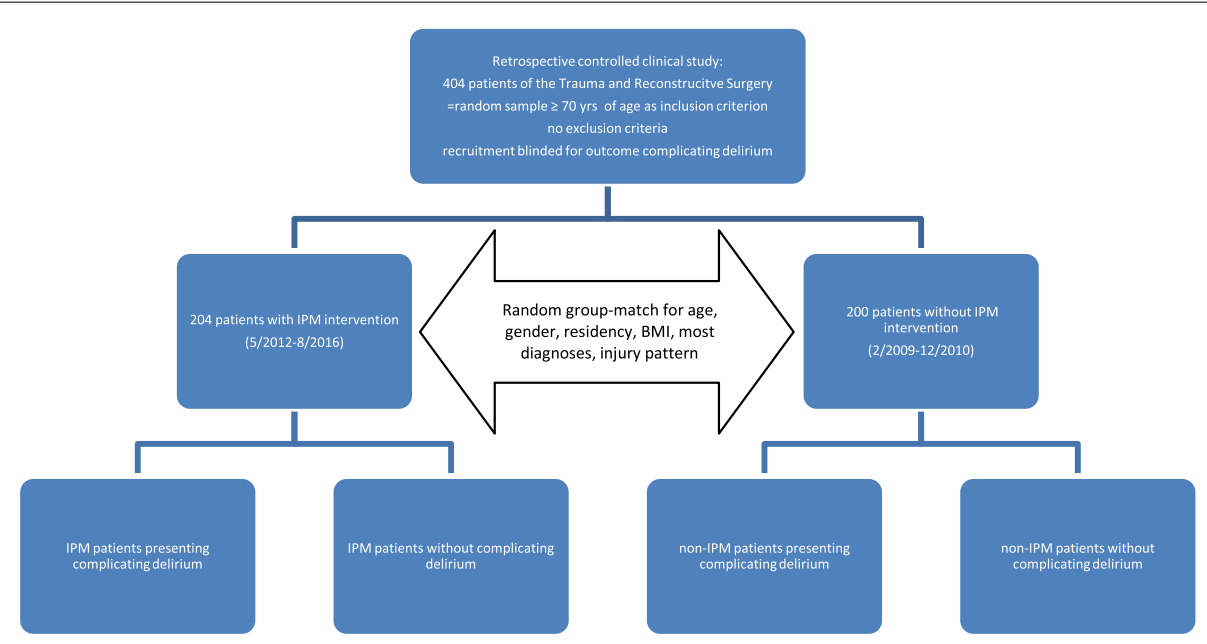

Fig. 1 Design of the retrospective controlled clinical study, patient recruitment and group-matched confounders 
key conditions met in order to adequately compare the two groups excluding decisive confounders for outcome.

There were no relevant changes in perioperative medical or nursing management over time. The spectrum of trauma and fractures also remained almost constant, and there were no discernible changes relevant to the analysis. Since being employed in the Department of Trauma Surgery at the University Hospital Halle and in particular since his position as senior physician in this from 2008 onwards, always this same senior physician in geriatric traumatology has been acting as a contributing team leader in terms of a multimodal delirium prevention involving physicians and nursing staff of the ward with established prevention approaches since then. This applies equally to the control and intervention groups. Since 2008, throughout the entire survey period including both, CG and IG, delirium prevention remained a multimodal approach that consistently focused on reorientation, optimized hydration, early mobilization, appropriate pain management, and early diagnosis for timely treatment of infection. IPM implementation started on an ongoing basis in 2011 as a step-up to optimize care and minimize further or repeated risk for these elderly and oldest-old patients from polypharmacy or even single medical agents. The multimodal preventive approach before and alongside IPM was not declared non-pharmacological, as in terms of early intervention for infections, this aspect was always integrated.

\section{IPM intervention}

The standardized, reproducible three-stage procedure of the implemented IPM (Fig. 2) always synoptically considers internistic and clinical-pharmacologic aspects due to the professional qualification and expertise of the responsible physician. IPM is based on the fully digitalized patient medical record by a hospital information system software (Orbis system) in the clinical environment. It provides the medication reviewer with a comprehensive "view" of the individual patient with his/her medication list, diagnoses, surgeries, updated laboratory (organ functions) and vital signs, ECG (Table 1) and ongoing clinical documentation from colleagues. The resulting IPM after Wolf (Fig. 2) takes into account the drug-specific professional information of all medications, medical guidelines and, if necessary, further clarifying updated PubMed searches. Indications and contraindications, warnings, additive effects, adverse drug reactions, pharmacodynamic and/or pharmacokinetic drug interactions, overdoses, duplicate prescriptions, missing prescriptions, erroneous prescriptions, temporal aspects of use/application/incompatibilities are recorded and reviewed. Finally, for all patients visited, individual therapy recommendations are implemented immediately after presentation of identified risks from drug effects, ADR, and drug interactions in an interdisciplinary consensus. Both, the further drug regimen and the therapy changes made are communicated as recommendations to the patient's physician providing outpatient treatment.

\section{Data collection}

We focussed on the outcome "complicating delirium". The defined "complicating delirium" is our clinical definition to select and determine the most robust manifestation of delirium that as a consequence is consistently documented in the patient hospital discharge letter. The discharge letter includes all diagnoses and information on the inpatient pre-, peri-, and post-operative course with reference to any kind of adverse or unexpected events or complications. To date, there are no references or definitions in the literature for severe delirium. "Complicating delirium "was defined as a delirium necessitating further investigations as laboratory parameters, cranial computed tomography or magnetic resonance imaging, and/or psychiatric consultation. In the context of the diagnostic assessment of the complicated clinical delirium situation, the described consecutive examinations were protocolized in the discharge letter as an additionally indicated diagnostic procedure to further investigate the patient delirious status. Complicating delirium simultanesously encompasses both, the criteria of the DSM-4 as well as the current DSM-5; among others, the presence of disorders of attention and consciousness and at least one other cognitive deficit developed over hours or a few days [21]; and it includes hyperactive, hypoactive, and mixed subtypes. For the anonymously sampled 404 patients, a total of 115 parameters (if available online) were recorded from the digital hospital information system Orbis (Table 1). Medication data were collected from the most comprehensive medication list during the patient's hospitalization, thus including transient antibiotics.

\section{Literature search}

The literature search was conducted online via PubMed - NCBI from November 2016 to January 2021. To obtain a comprehensive overview of recent national and international studies, we used the following search terms: 'delirium in elderly people, 'drug-induced delirium,' 'delirium polypharmacy', 'delirium post surgery elderly', 'postoperative delirium in the elderly', 'delirium definition, 'delirium postoperative elderly epidemiology', 'postoperative delirium prevention', 'delirium medication review', 'delirium medication analysis', 'delirium prevention. We applied the filter "Species: Humans." Literature management and citation was done with Citavi version 5.5.0.1. 


\section{Individual Pharmacotherapy Management according to Wolf* - IPM}

\section{Details Procedure Medication Review (Ursula Wolf, MD)}

Workload ( 6.5 minutes/patient $=9.2$ patients/hour)

\section{$\rightarrow 1$. Actual patient condition $="$ digital overall view of the patient" capturing}

1.1 All current medications including the admission medication 1.2 Entire diagnoses, surgeries and the current clinically relevant problems (note changes)

1.3 Laboratory parameters (organ functions liver, kidneys, myelopoiesis, coagulation, thyroid gland, etc. (note changes \& machine replacement therapies), electrocardiogram 1.4 Vital parameters, especially in the course, including the cardiopulmonary situation 1.5 Acquisition of continuous patient history documentation from colleagues.

$\rightarrow$ 2. Review of all applied medications digitally via their Summary of Product Characteristics and their application to the updated patient situation (see above):

2.1 Evidence for contraindications?

2.2 Warnings?

2.3 Additive effects?

2.4 Adverse and additive adverse drug reactions?

2.5 Drug interactions, pharmacodynamic and/or pharmacokinetic?

2.6 Overdoses?

2.7 Possible duplicate prescription, missing prescription, misprescription?

2.8 Mode of application? Adjustments intravenous, peroral, tubes?

2.9 Temporal aspects of application/incompatibilities?

\section{$\rightarrow$ 3. Visitation and interdisciplinary networking with pharmacotherapy adaptation}

Synoptic internistic/clinical-pharmacologic medication review

(taking into account the Summary of Product Characteristics for each substance, guidelines, current PubMed research, if necessary) and communicating the results through interdisciplinary patient rounds or immediate telephone transmission to the attending colleague(s) with consensual decisions on an adapted therapy.

*Comprehensive, digitally based IPM, developed, implemented and practiced by Ursula Wolf, MD, Head of the

Pharmacotherapy Management Department, specialist in Internal Medicine and expertised in Clinical Pharmacology, performed $>38,000$ individual medication reviews.

Fig. 2 IPM procedure after Wolf*

\section{Statistical analysis}

Statistical analysis was supervised by the consulted Institute of Medical Epidemiology, Biometry, and Informatics. We used Microsoft Excel 2016 for anonymous data collection and SPSS Statistics 24 for data analysis. After descriptive analysis of the two groups and univariable logistic regression in relation to complicating delirium, we performed multivariable regression analysis for all variables with a $p$ value $\leq 0.05$ to measure the association with this outcome, adjusting for confounders and using a $95 \%$ confidence interval (CI) to correct for multiple testing. We performed logistic regression analysis including the entire study population to identify independent factors associated with complicating delirium.

\section{Results}

Descriptive analysis of the IG $(n=204$ patients) and the CG ( $n=200$ patients) in terms of baseline data as age, gender, residency, BMI (Fig. 3) and injuries leading to admission (Fig. 4) showed a comparable distribution pattern over the entire observation period. 
Table 1 Variables collected for data analysis and included in the individual medication review

- Demographics: age, gender, type of residence (home/nursing home)

- Vital parameters at admission: BMI, blood pressure (day course), heart rate (day course)

- Continuous and acute medication: number of drugs, Angiotensin converting enzyme inhibitors (ACE inhibitors), sartans, calcium antagonists, differentiated ß-blockers, a-blockers, antibiotics, antifungals, antiarrhythmics, antidementives, anticonvulsants, different oral anticoagulants, bisphosphonates, different antiplatelet drugs, different diuretics, antipsychotics, antidepressants, St. John's wort, oral antidiabetics, insulin, antiparkinsonian drugs, benzodiazepines, proton pump inhibitors (PPI) (incl. dosage), ophthalmics, urological drugs, muscle relaxants, opioids, "Würzburger pain drip" tramadol, nonsteroidal anti-inflammatory drugs (NSAIDs), further analgesic agents, antiemetics, thyroid hormones, xanthines, uricosurics, uricostats, statins, vitamin D, corticosteroids, other drugs (e.g. hormones, cytostatics)

- Laboratory parameters at admission: blood count, electrolytes, inflammation parameters, renal function parameters during course of stay, myoglobin, coagulation parameters, urinalysis

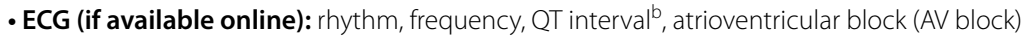

- Diagnoses ${ }^{\complement}$ : arterial hypertension, heart failure, severe delirium, cognitive impairment to dementia, Parkinson's disease, further central nervous system (CNS) disorders, chronic obstructive pulmonary disease (COPD), diabetes mellitus, osteoporosis, chronic kidney disease

- Additional course aspects: changes in laboratory findings, blood pressure, heart rate, temperature, cognitive changes/disturbances, pain symptoms and profile, other subjective complaints of the patient

- Other parameters: acute admission injury, operation, transient stay in IMC ${ }^{d}$ or ICU ${ }^{e}$, hemodialysis, length of hospital stay, perioperative infections, fall risk scale according to Huhn (0-31 points, broken down according to: age, mental status, excretion, history of falls, gait/balance, activities, medication, alcohol), pacemaker, defibrillator, infections requiring antibiotics, contrast medium application

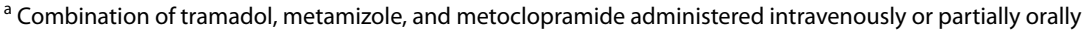

${ }^{b}$ time from the start of the $Q$ wave to the end of the T wave (measurement on ECG)

' coded in the hospital discharge letter

${ }^{\mathrm{d}}$ Intermediate care

${ }^{\mathrm{e}}$ Intensive care unit
}

In both groups, the trauma patients were almost oldest-old and predominantly female (71\% in each group) (Fig. 3). Most patients (80\%) lived in their own homes. More than $80 \%$ of patients in both groups required surgical intervention. The similar number of prescribed medications averaged $11.1 \pm 4.9$ in the CG and $10.4 \pm 3.6$ in the IG. The two groups differed only slightly in the distribution pattern of concomitant diagnoses (Fig. 3). Pre-existing central nervous system (CNS) diseases, excluding Parkinson's disease and cognitive impairment to dementia, were slightly more frequent in the IG, less frequent cognitive impairment. The prevalence of AV block I-III in the 80 available ECGs was the same in both groups (21\%). Laboratory parameters analyzed included hemoglobin content and glomerular filtration rate (according to the Berlin Initiative Study eGFR equations (BIS formula)), leukocytes, mean corpuscular volume (MCV), and serum sodium. In addition to the similar prevalence of anemia in both groups (Fig. 3), increased MCV as a possible indication of vitamin B12 and/or folic acid deficiency anemia was equally distributed in macrocytic anemia, and the same was true for microcytic hypochromic anemia. Leukocytosis was found in $42 \%$ of patients in CG and $46.6 \%$ in IG. A glomerular filtration rate (GFR) G3 according to KDIGO (Kidney Disease: Improving Global Outcomes) was present in 53\% in the CG and $58.3 \%$ in the IG. Only one-third of patients in both groups had normal renal function. The prevalence of chronic kidney disease shown in Fig. 3 can be further broken down according to the GFR determined here by BIS. There was no difference between the control and intervention groups in terms of different severity levels. Hyponatremia present at admission was found in both patient groups with CG 6.5\% and IG 10.3\%. Regarding blood pressure values measured during the course of a hospital day, $18.5 \%$ of patients in the CG and $12.8 \%$ in the IG had hypotensive blood pressure values (systolic $<120 \mathrm{mmHg}$ ).

Primarily, $50 \%$ of patients in both groups were affected by traumatologic injuries to the lower extremity (Fig. 4). Only the prevalence of spinal injuries was higher in the IG. Injuries to the upper extremity, head, or several concurrent injuries on admission were almost equally distributed.

The individual medication data analyses focused on all different drug groups and we compared the distribution frequencies of the entire perioperative medications of both groups (Fig. 5).

In particular, differences in the prescription rate of medications switched by the IPM were evident. The "Würzburger pain drip" was almost withdrawn from 52,2 to $2.0 \%$ in the IG. NSADs, metoclopramide, and benzodiazepines were reduced in the IG. In contrast, to compensate for this, prescription of non-serotonergic opioids, as well as paracetamol, and metamizole increased in the IG. Thiazides and allopurinol were reduced in IG. Consistent with their more recent approval, direct oral anticoagulants predominated in IG. Within the PPI doses distributions, the IG reduction of inadequately high PPI doses 


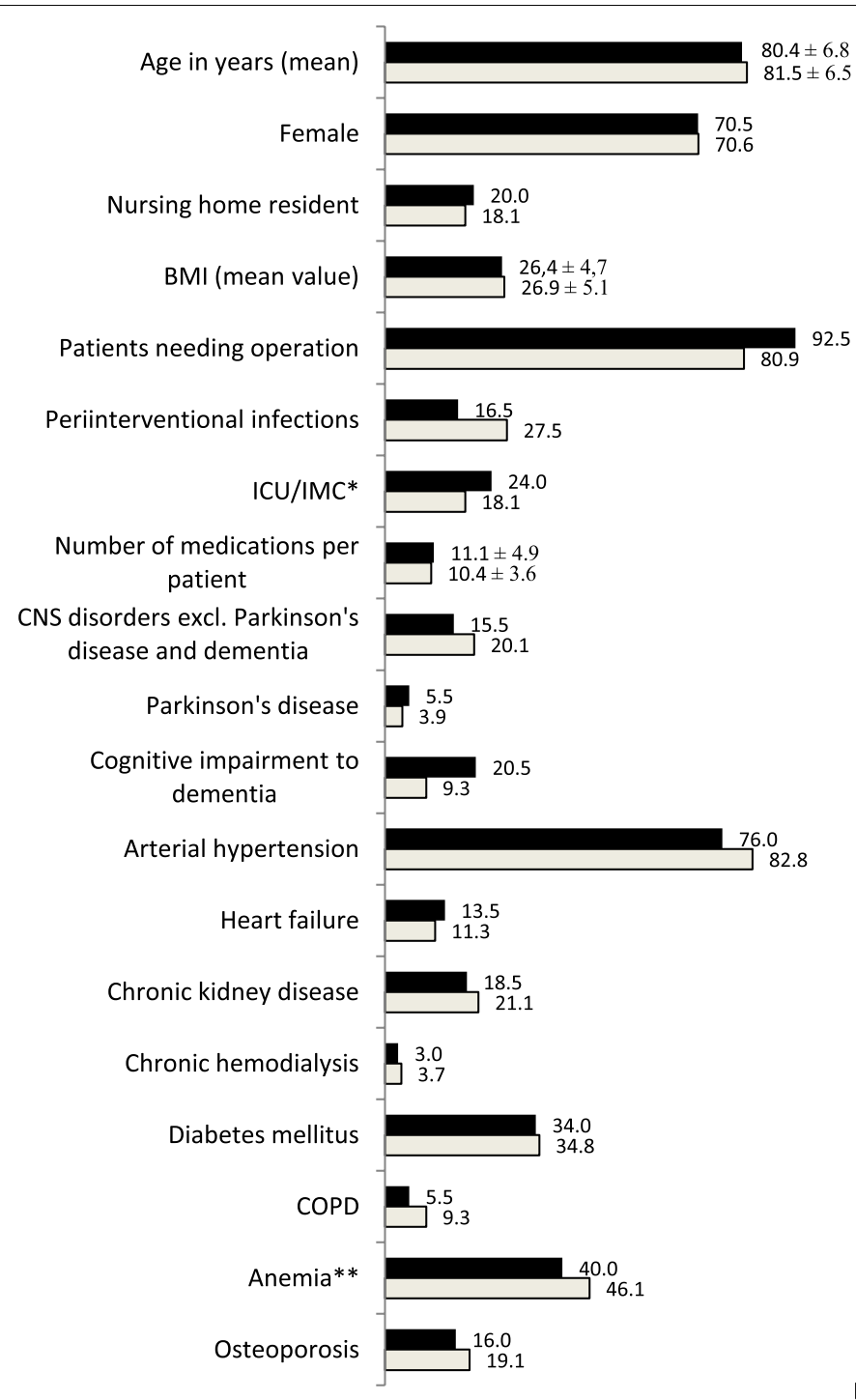

- Control group

$\square$ Intervention group

${ }^{*}$ Transient stay in the intensive care unit or intermediate care; "*Anemia: hemoglobin in women $<7.1 \mathrm{mmol} / \mathrm{l}$, in men $<8.4 \mathrm{mmol} / \mathrm{l}$

Fig. 3 Baseline data and diagnoses comparing control and intervention group (Percentage prevalence numbers (\%) except mean values \pm standard deviation (SD) for age, BMI, and number of medications)

from 40 to $20 \mathrm{mg}$ stands out as an adapted adequate and only transient prophylactic dose in the perioperative setting. Antibiotics were applied more frequently in IG (27.5\%) than in CG (16.5\%) (Fig. 5).

Due to the short inpatient length of stay in the perioperative setting and the fact that many drugs require gradual deprescribing approach, the therapeutic effect of the drug therapy recommendations of the IPM could only be partially captured. In addition, we did not consider the frequent approach of dose reductions in this data analysis.
Complicating delirium manifested in $5 \%$ of patients in the CG (10 of 200 patients) and $0.5 \%$ in IG ( 1 of 204 patients) (Fig. 6).

Affected patients in CG were predominantly male ( $8.5 \%$ of 59 men versus $3.5 \%$ of 141 women).

In IG, IPM reduced the risk of complicating delirium by $90.2 \%$. Gender distribution was the same in both groups.

Univariable logistic regression from all variables revealed the following confounders with clinically relevant association with complicating delirium, defined with a strong odds ratio $(\mathrm{OR}) \geq 2$ or $\leq 0.5$ (Table 2 ). 


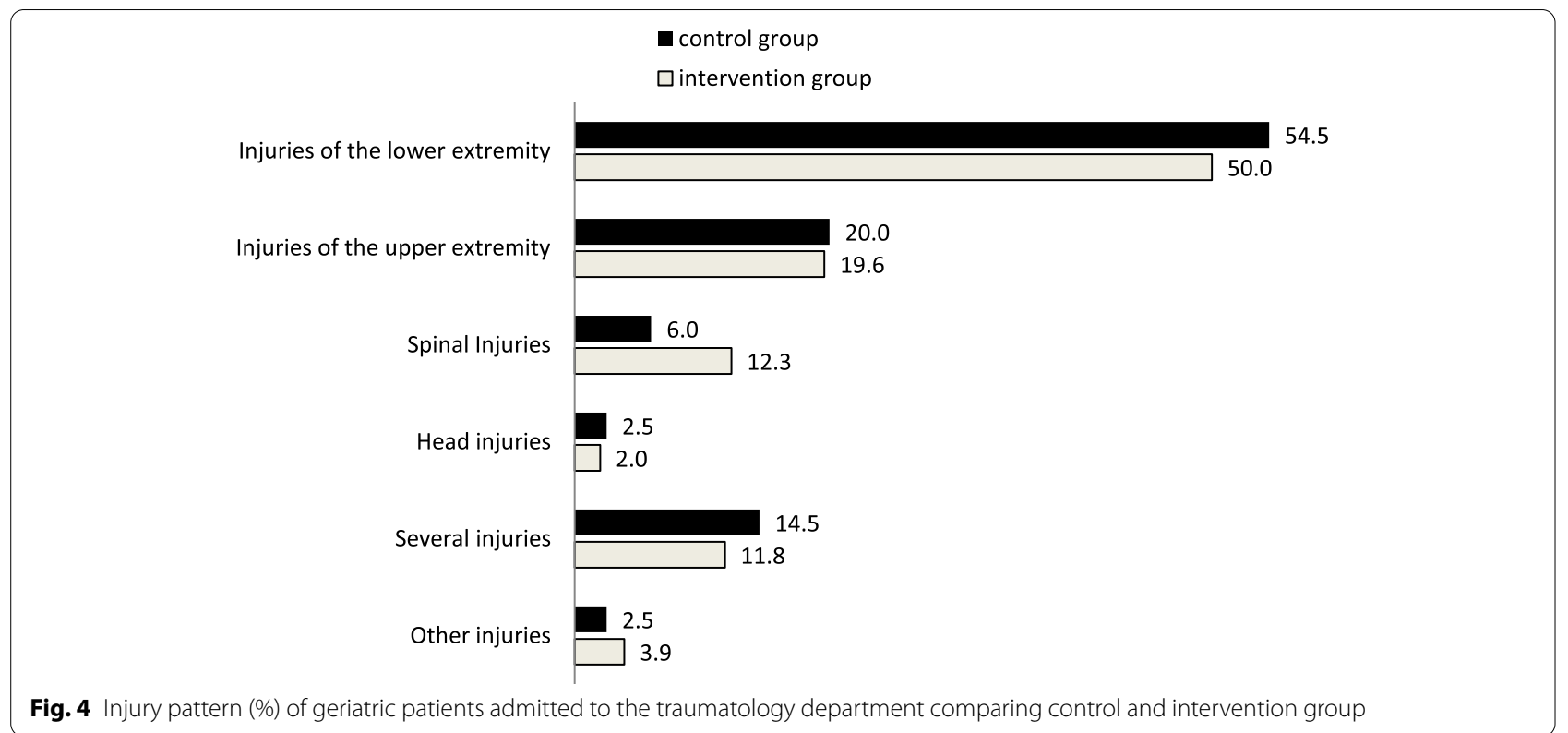

A relevant association with a strong $O R \geq 2$ was found with both preventable factors such as in-hospital falls, inserted urinary bladder catheter, anemia, body mass index $(\mathrm{BMI}) \leq 20 \mathrm{~kg} / \mathrm{m}^{2}$, dementia, and various medications, and with invariant or less variable factors such as gender, chronic hemodialysis, nursing home residency, and Parkinson's disease. Items from Huhn's fall risk scale (collected by nursing staff on inpatient admission) such as temporary or permanent disorientation, bladder catheter or enterostoma, incontinence, occasional alcohol consumption were associated with delirium. Other less pronounced associations $(\mathrm{OR}<2)$ were seen with: Hyponatremia, type of injury on admission, leukocytosis, benzodiazepines, metoclopramide, tramadol, and "Würzburger pain drip", the latter with an OR $=1.68$ [95\% CI 0.36-7.91].

Multivariable regression analysis was performed with all confounders revealing an association with $p$-value $\leq 0.05$ and is shown in Table 3. To achieve sufficient test power with a patient number of 404, the variable "atrial fibrillation" was excluded due to the small number $(n=80)$ of digitally available ECGs. The resulting $\mathrm{OR}>1$ after all adjusted variables indicate that there remains an independent increased association of the variable with the occurrence of complicating delirium. Only IPM was associated with an independent tenfold risk reduction for complicating delirium, according to the multivariable model.

\section{Discussion}

The study documents a high association of the applied IPM as a synopsis of internal medicine and clinical pharmacology with the reduction of complicating delirium in geriatric trauma patients. Still underrepresented in previously published study data, it potentially contributes as a preventive tool to improve patient care and patient safety in a clinically relevant way. Our data additionally confirm further and partly established factors associated with increased incidence of complicating delirium, including special drug groups.

The incidence of complicating delirium, $5 \%$ in the control group, is lower than in figures from the current literature, as the latter mostly include the entire spectrum of delirium. They range from 12 to $51 \%$ in different studies $[1,9,15,23,24]$. The large discrepancy between these literature studies can be partly explained by the different assessment of delirium and the difficulties in adequately recognizing it in extent, especially for the hypoactive form. Therefore, we focused on a more robust form of delirium for comparison, namely the concise manifestations complicating hospitalization as documented in the hospital discharge letter, although it is reasonable to assume that there is a higher incidence of noncomplicating or less pronounced manifestation of delirium after traumatology procedures. However, the certainty of an impressive reduction in the robust form of our defined complicating delirium by IPM remains, as possible documentation deficits would have to be assumed with continuity of responsibilities in CG and IG alike. In addition, the briefing of the staff and the detailed self-history we apply, as well as the patient's history by relatives or others, help as an important prerequisite to distinguish dementia from delirium from the outset. Because different subtypes of delirium are often less accurately documented, we must be aware of a higher incidence of clinically less prominent delirium, which was purposefully not 


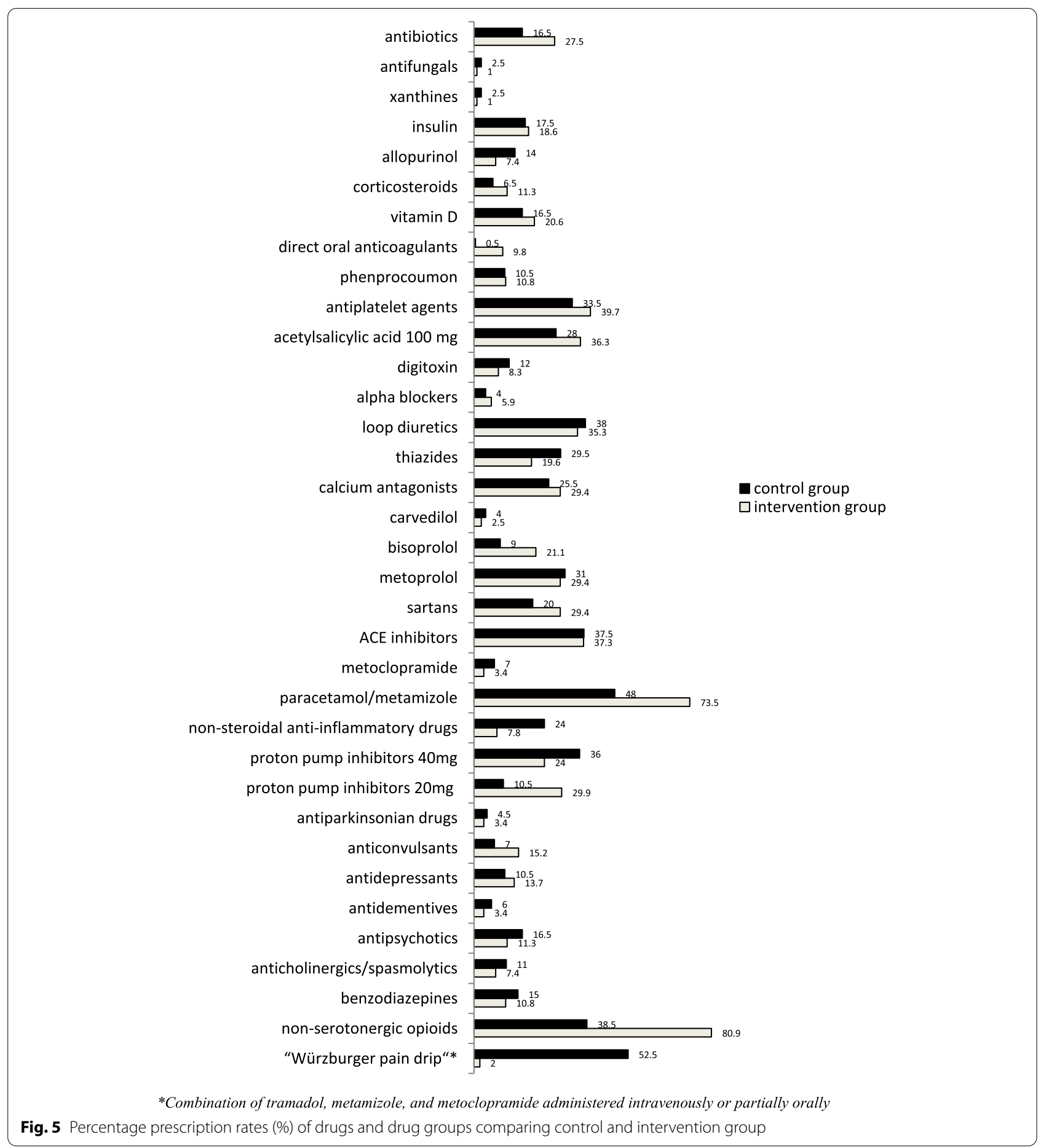

included in our definition of complicating delirium for either group because of the assumed uncertain documentation. Meagher et al. [25] applied three assessments for delirium subtype identification in their longitudinal study of 100 palliative care patients: the Delirium Motor Subtype Scale (DMSS), the Delirium Rating Scale-Revised-98
(DRS-R98), and the Cognitive Test for Delirium (CTD). Delirium phenomenology was stable during delirium episodes in $62 \%$. Subtypes differed in non-cognitive symptoms but not in cognitive subscale scores. The latter should therefore be preferred to identify less obvious manifestations [25]. The possibility of a longitudinal 


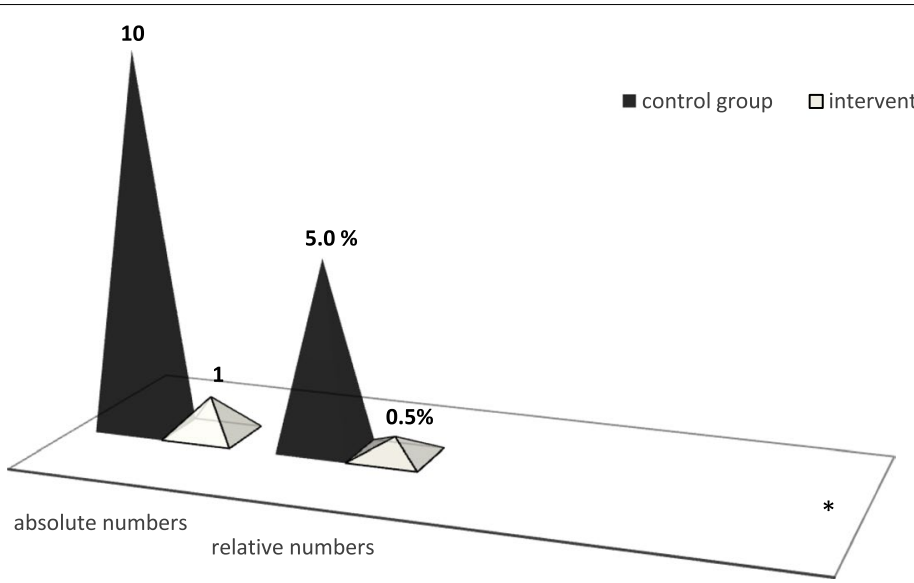

*The pyramid shape is meant to indicate that the closer one gets to the base or zero point, the more challenging it is to downsize the delirium pyramid, since it is difficult to completely eliminate all components of its multifactorial genesis.

Fig. 6 Incidence of complicating delirium comparing control ( $n=200$ patients) and intervention group ( $n=204$ patients)

study design on ongoing episodes of delirium in the palliative care may reflect its typical socalled the "best supportive care "(BSC) situation resulting from its inherently frequent application of combined psychotropic drugs, sedatives, and analgesics with resulting ADR and pharmacodynamic and pharmacokinetic interactions. Moreover, the palliative care group also frequently suffers from organ dysfunction that slows the capacity of drug metabolism and renal elimination, so attention must be paid to compensatory drug dose adjustment. Focusing on dose adjustment in relation to laboratory data on organ function has been a common process within IPM that is not further quantified here. This essentially requires knowledge of the exact drug metabolism/excretion in the human body from its drug-specific professional information as a profound basis of applied IPM.

The tenfold reduction of complicating delirium in association with IPM is clinically relevant. This is also related to the consistent implementation of IPM over years including a complete restructuring of the drug pain management. Withdrawal of tramadol and other serotonergic opioids proved to be an important step in this process. Presumably, there is an unconsidered overlap with serotonin syndrome in the diagnosis of delirium, as elderly patients often take serotonergic agents, e.g., from the broad spectrum of antidepressants, which should not be combined with serotonergic opioids.

On average, the number of preset medications was similar in both groups, and the need for perioperative analgesics and possibly antibiotics cannot be excluded. The common finding from the international literature is that medications and polypharmacy can promote or even trigger delirium $[1,7,16,26]$.
Masnoon et al. found 138 definitions of polypharmacy, a large proportion of which were simply quantification of medications taken [8]. Only $6.4 \%$ of the articles distinguished between adequate and inadequate polypharmacy. However, they also pointed out that a purely numerical definition makes it difficult to ensure safety and appropriateness in clinical practice. This is consistent with our data. The approximately equal number of medications taken in the control and intervention group suggest that, as described by Masnoon et al., it is not only the amount of medication that contributes to the development of delirium [8]. Moreover, medication of elderly and often multimorbid patients should be regularly and critically reviewed, as performed in a very comprehensive way by the presented IPM procedure, with additional focus on elimination of drug interactions, overdosage, attention to warnings and ADR often even cumulative.

In this context, early withdrawal of the "Würzburger pain drip" consisting of a fixed combination of tramadol, metoclopramide, and metamizole was an essential step of IPM with a potential "superior" long-term class effect. Some of these drugs have a high potential for interaction with synergistic ADR and even reciprocal influence on enzymatic metabolism and excretion rate. Metamizole can lead to acute deterioration of renal function and even acute renal failure [27]. Metoclopramide acts through its dopamine receptorblocking mechanisms in the CNS. Even a single dose can lead to extrapyramidal symptoms and, in combination with antipsychotics, can cause malignant neuroleptic syndrome. Intravenous administration in elderly patients with existing conduction disorders, uncorrected electrolyte shifts or bradycardia promoted 
Table 2 Variables showing a clinically relevant association (defined as a strong $O R \geq 2$ or $O R \leq 0,5$ ) with complicating delirium (univariable regression analysis including all patients $n=404$ )

\begin{tabular}{|c|c|c|c|c|}
\hline & $P$-value & Odds ratio & 95\% Confidence interval & Total number \\
\hline IPM & 0.03 & 0.09 & $0.01-0.7$ & 204 \\
\hline Cognitive impairment to dementia & 0.001 & 9.5 & $2.7-33.5$ & 68 \\
\hline Nursing home resident & 0.001 & 8.1 & $2.3-28.3$ & 77 \\
\hline Intensive care stay & 0.012 & 4.8 & $1.4-16.0$ & 85 \\
\hline Anemia & 0.17 & 2.4 & $0.7-8.1$ & 174 \\
\hline $\mathrm{BMl} \leq 20 \mathrm{~kg} / \mathrm{m} 2$ & 0.4 & 2.5 & $0.3-21.5$ & $19\left(m^{\prime} 62\right)$ \\
\hline COPD & 0.2 & 2.9 & $0.6-14.1$ & 30 \\
\hline Diabetes mellitus & 0.2 & 2.3 & $0.7-7.8$ & 139 \\
\hline Infection requiring antibiotics & 0.003 & 6.6 & $1.9-23.2$ & 89 \\
\hline Fall in hospital & 0.2 & 2.8 & $0.5-13.5$ & 31 \\
\hline Men & 0.2 & 2.0 & $0.6-6.8$ & 119 \\
\hline Parkinson's disease & 0.05 & 4.9 & $1.0-24.5$ & 19 \\
\hline Chronic hemodialysis & 0.3 & 3.2 & $0.4-26.8$ & 13 \\
\hline Atrial fibrillation & 0.05 & 12.0 & $1.0-143.9$ & $13\left(m^{\prime} 324\right)$ \\
\hline Antipsychotics & 0.001 & 12.3 & $3.5-43.5$ & 56 \\
\hline NSAIDs & 0.3 & 2.0 & $0.5-7.9$ & 64 \\
\hline Paracetamol / Metamizole & 0.2 & 3.0 & $0.6-13.9$ & 246 \\
\hline Muscle relaxants & 0.2 & 4.8 & $0.5-42.2$ & 9 \\
\hline Digitalis & 0.4 & 2.0 & $0.4-9.7$ & 41 \\
\hline Corticosteroids & 0.3 & 2.3 & $0.5-11.3$ & 36 \\
\hline Antifungal drugs & 0.09 & 6.5 & $0.7-58.7$ & 7 \\
\hline Memantine & 0.4 & 2.5 & $0.3-20.8$ & 16 \\
\hline Antiparkinsonian drugs & 0.03 & 6.0 & $1.2-30.5$ & 16 \\
\hline Xanthines & 0.002 & 17.2 & $2.9-101.0$ & 7 \\
\hline Fall risk scale according to Huhn & & & & $394\left(m^{\prime} 10\right)$ \\
\hline temporarily disoriented & 0.006 & 6.7 & $1.7-26.1$ & 41 \\
\hline permanently disoriented & 0.1 & 3.6 & $0.7-19.0$ & 37 \\
\hline occasional alcohol consumption & 0.1 & 2.9 & $0.7-11.4$ & 46 \\
\hline restrictions in mobility & 0.2 & 3.7 & $0.5-29.5$ & 136 \\
\hline bladder catheter / enterostoma & 0.1 & 3.6 & $0.6-19.9$ & 90 \\
\hline bladder / stool incontinent & 0.2 & 3.9 & $0.5-28.9$ & 41 \\
\hline
\end{tabular}

$\mathrm{m}^{1}$ missing values

QT prolongation, AV block, sinus arrest, torsade de pointes, and cardiac arrest [28]. Tramadol exerts its analgesic effect through opioid, serotonergic and noradrenergic receptors [29]. It can cause hallucinations, confusion, and changes in cognitive and sensory performance, leading to the development and increased incidence of delirium [30].

Tramadol additionally accumulates in renal insufficiency and requires early adaption, which is often overlooked. Both, tramadol and metoclopramide are substrates of the highly polymorphic monooxygenase cytochrome P450 2D6 (CYP2D6), which has a high affinity and low capacity for its substrates, resulting in reduced drug efficacy especially when prodrugs such as tramadol must be activated by CYP2D6. Approximately $20-25 \%$ of all drugs used are metabolized by CYP2D6, but nearly $50 \%$ of all drugs used in the clinical setting (including antidepressants, antiemetics, beta-blockers, psychotropic drugs, and opioids) undergo this metabolism. In addition, the pharmacogenics regarding CYP2D6 polymorphism influences drug levels. It must be taken into account that undetected poor metabolizers account for $5-10 \%$ and $5 \%$ of all Western Europeans are considered CYP2D6 ultrarapid metabolizers [31, 32]. Switching from intravenous "Würzburger drip pain" to preferential peroral or subcutaneous administration of hydromorphone or tilidine/naloxone retard has been part of the successful reduction of complicating delirium. Tilidine 
Table 3 Measures of association with complicating delirium from multivariable regression analysis including variables with $p$-value $\leq 0.05$ from univariable regression

\begin{tabular}{|c|c|c|c|c|}
\hline & $P$-value & Odds-ratio & 95\% Confidence interval & Number \\
\hline IPM & 0.06 & 0.1 & $0.01-1.1$ & 204 \\
\hline Cognitive impairment to dementia & 0.3 & 2.8 & $0.3-22.9$ & 68 \\
\hline Nursing home resident & 0.3 & 2.7 & $0.4-17.5$ & 77 \\
\hline Intensive care stay & 0.05 & 5.2 & $1.0-27.1$ & 85 \\
\hline Infection requiring antibiotics & 0.1 & 3.5 & $0.7-18.4$ & 89 \\
\hline Antipsychotics & 0.01 & 8.2 & $1.6-42.6$ & 56 \\
\hline Muscle relaxants & 0.2 & 15.6 & $0.3-728.7$ & 9 \\
\hline Antiparkinsonian drugs & 0.5 & 2.4 & $0.2-30.3$ & 16 \\
\hline Xanthines & 0.05 & 11.8 & $1.0-132.8$ & 7 \\
\hline Antifungal drugs & 0.7 & 1.9 & $0.1-34.9$ & 7 \\
\hline $\begin{array}{l}\text { Fall risk scale according to Huhn - Temporarily } \\
\text { disoriented }\end{array}$ & 0.5 & 1.7 & $0.3-9.9$ & 41 \\
\hline
\end{tabular}

is preferable to tramadol as a pure opioid agonist with greater analgesic potency and especially regarding psychiatric symptoms. The sustained-release form ensures uniform analgesia over $12 \mathrm{~h}$, and impaired renal function does not lead to accumulation of pharmacologically active metabolites.

In hepatic impairment, the maximum plasma concentration of the active metabolite nortilidine is lower and the half-life is prolonged. It is subject to a first-pass mechanism and is metabolized by cytochrome $\mathrm{P} 450$ 3A4 (CYP3A4) and cytochrome P450 2C19 (CYP2C19), among others, so restriction with potent analog inhibitors is required. Concomitant administration with serotonergic drugs may increase the risk of serotonin syndrome [33].

The unretarded form of hydromorphone, a $\mu$-selective, pure opioid agonist, has been used to break through pain peaks. Because there is no opioid without an ADR, it can occasionally cause agitation, depression, euphoria, hallucinations, and nightmares [34]. Perioperatively we primarily use the sustained-release hydromorphone as a basic analgesic in combination with the unretarded form as an on-demand medication. After a few days postoperatively and especially at discharge, we de-escalate to tilidine. Only for minor injuries and minor surgical procedures do we start with tilidine from the beginning.

In univariable observation, we found other factors associated with complicating delirium. This is reflected analogously in the various studies on delirium. In their metadata analysis of 10 prospective observational studies on preoperative risk factors, Oh et al. describe cognitive dysfunction as a relevant influencing factor for delirium [26]. Other studies also identify cognitive dysfunction as an important associated factor $[1,15,35]$.
A BMI $<20 \mathrm{~kg} / \mathrm{m}^{2}$ is documented as an influencing factor by Oh et al. [26] and Juliebo et al. [35]. There are further risk factors for delirium that are consistent with the association results of our study. These include nursing home residency [26], infections [1, 2], male gender [5], Parkinson's disease [9], and antipsychotics [23].

Algiakrishnan et al. [7] detected an influence of various drugs on delirium, which was also found in our analysis: NSAIDs, muscle relaxants, digitalis, glucocorticoids, xanthines and antiparkinsonian drugs, benzodiazepines, and antiemetics. However, the total number of some drug groups in our cohorts is rather low. While both Raats et al. [36] and Myint et al. [37] found no association between preoperative anemia and postoperative delirium, our data showed at least a clinically relevant association with anemia with a more than doubled OR. The included age group of our patient collective was $\geq 70$ years, and on average, patients in both groups were almost oldest-old at approximately 80 years. Oh et al. [26] could find six studies in which age showed a univariable association with delirium and two studies in which there was a significant association with the development of delirium after adjustment in the multivariable model. However, in the present study, no relevant association was found for age and delirium. The discrepancy may be partly due to the continuing difficulty in defining "age." Many studies refer only to "old age" or the "elderly patient" [10, 26, 38]. Following the Lancet article by Beard et al. on the first World Health Organization (WHO) World Report on Aging and Health, old age/frailty may be seen as the progressive decline of physiological systems leading to increased vulnerability to stressors, resulting in negative risks such as need for care and death [39]. According to Beard et al., it is more an individual aspect and depends, for example, on socioeconomic status, among other factors, and also 
increases with numerical age. They postulate that the state of health in old age should not be determined by the presence or absence of disease, but should focus on the individual's ability to function. The problem of complex definition is also evident in German-speaking countries; the widely used potentially inappropriate medication in the elderly (Priscus) list for assessing inadequate medication in elderly patients does not provide a definition for "elderly patients." An important negative aspect of tools to improve polypharmacy in the elderly, such as the Medication Appropriateness Index (MAI), the Beers list or the Priscus list, the Fit fOR The Aged (FORTA) and the Screening Tool of Older Persons' Prescriptions - Screening Tool to Alert to Right Treatment (STOPP-START), is that they can never capture the complex individual polypharmacy situation with drug interactions and organ functions in multimorbidity, as ensured by IPM. This may be the main reason for the very successful effect of "IPM according to Wolf", which has not been achieved by any other intervention or strategy so far.

Multivariable regression showed an $\mathrm{OR}=5.2[95 \% \mathrm{CI}$ $1.0-27.1], p=0.05$, for an ICU/IMC stay, several studies confirm the independent impact of ICU stay on the development of delirium [40, 41]. Galyfos et al. analyzed 9 studies and described this as one of the most important associated factors with an OR $=6.12[95 \% \mathrm{CI}$ 4.7-7.9] [42].

Regarding blood pressure measured during the day course in hospital, $18.5 \%$ of patients had hypotensive blood pressure values (systolic $<120 \mathrm{mmHg}$ ) in the CG and $12.8 \%$ in the IG, but no relevant association with delirium emerged from univariable regression. Studies on the impact of perioperative hypotension are controversial. Wesselink et al. could not find a significant correlation between intraoperative hypotension and the development of delirium in on-pump cardiac surgery [43]. Hirsch et al. were able to establish an association between increased blood pressure fluctuations and the development of delirium during noncardiac surgery, but none with hypotension [44]. Nguyen et al. found a relationship between the development of delirium and low diastolic blood pressures $(<60 \mathrm{mmHg})$ in shock patients [45].

The higher preference of antibiotics in the intervention group is probably a consequence of the more numerous positive bacterial evidence in urinalysis.

Overall, $46.5 \%$ of patients in the CG and $53.9 \%$ in the IG were taking preset proton pump inhibitors. The inadequate and widespread prescribing of PPI in uncontrolled overdose appears to be related in part to the increased prescribing of direct oral anticoagulants and the increasing rate of use of antiplatelet agents as intended prophylaxis for gastrointestinal bleeding.
With a concerning registration of predominantly preset therapeutic dosages of $40 \mathrm{mg}$ daily rather than $20 \mathrm{mg}$ prophylactically, our IPM aimed to adequately reduce the dosage of, for example, pantoprazole and omeprazole from 40 to $20 \mathrm{mg}$ daily for perioperative stress ulcer prophylaxis. This IPM measure resulted in a deliberate reversal of the distribution frequency of the individual PPI dose favoring the adequate lower $20 \mathrm{mg}$ in IG.

According to their ADR or misindication in more advanced renal dysfunction in $2 / 3$ of the patients thiazides and allopurinol were deprescribed in IG. For chronic hemodialysis, an association was found in the univariable model, but since only 13 of the 404 patients were chronically dialyzed, it can only be evaluated to a very limited extent, as seen from the $95 \% \mathrm{CI}(\mathrm{OR}=3.2$ [95\% CI 0.4-26.8], $p=0.3$ ).

Hyponatremia at the time of admission was found in both patient groups, CG $6.5 \%$ and IG $10.3 \%$, but no association measure with complicating delirium. Wang et al. detected a correlation between postoperative hyponatremia and postoperative delirium after orthopedic surgery with an OR of 3.0 [46].

Interestingly, in the univariable regression, several items from the Huhn risk fall scale assessed by nurses during inpatient admission, such as temporary or permanent disorientation, bladder catheter or enterostomy, limitations in mobility, incontinence, and occasional alcohol consumption were associated with delirium. Approximately $1 / 3$ of patients described as cognitively impaired preoperatively develop postoperative delirium and have up to a 2-fold increased risk of mortality [1, 26, 47]. Cognitive impairment to dementia was analogously associated with complicating delirium in our study, with a clinically relevant OR of 2.8 in multivariable regression analysis.

Transient disorientation showed an OR almost twice as high compared with permanent disorientation, possibly indicating already mild manifestations or precursors of delirium. Regarding alcohol consumption, a urinary bladder catheter, and postoperative delirium, several studies $[1,7,9,40]$ documented an association. Brouquet et al. described a mobility restriction with $>20$ s lasting "timed get up and go" as a significantly associated factor [48].

Delirium prevention by medication review is an underrepresented approach. A 2019 Cochrane review of delirium prevention interventions in the elderly in institutional long-term care by Woodhose et al. identified evidence from only one cluster RCT that a software based intervention to identify medications that might contribute to delirium, applied to medication review, reduced delirium in this setting (12-month HR 0.42, CI 0.34 to 0.51) [49]. This supports our results, although we even 
achieved a tenfold reduction in complicating delirium due to our implemented strategy of individualized and thus more precise patient plus medication review. Hein et al. demonstrated polypharmacy as an independent risk factor for delirium in a population of elderly patients after emergency admission in an observational cohort study and documented a relative risk of 2.33 [50]. In a Dutch comparative retrospective cohort study, a medication review conducted by a clinical pharmacist and a geriatrician for delirium in elderly hospitalized patients showed significant clinical benefit in terms of shortening delirious episode by 6.91 days [51]. The American Geriatrics Society Expert Panel on Postoperative Delirium in Older Adults launched Evidence-Based Recommendation Statements as best practice statements [52]. They clearly recommend avoidance of medications prone to induce delirium postoperatively, which is supported in the Clinical Guidelines for Improving Medication Safety in Older Adults [53] published in 2012 and updated in 2019. Nearly 10 years apart, there does not appear to have been much, if any, change in the overall incidence of delirium described in hospitalized older patients. In the Nature Review, Disease Primers, Delirium 2020 Wilson et al. note that prevention strategies, among others, remain an important challenge worldwide. They also focus on neurotransmitter imbalance due to drug use as a trigger for delirium [54].

To our knowledge, the high effectiveness of our IPM, which always covers quite comprehensive patient aspects, for the prevention of complicating delirium is unique. Based on digital data access and many years of internal medicine and clinical pharmacology experience with more than 38,000 own individual medication reviews since 2011, IPM now takes an average of only 6,5 min per patient. Drug attention in delirium should be mandatory in the preventative approach.

The current German ICD-10 classification 2021 defines delirium in its main heading as a "brain-organic syndrome not caused by alcohol or other psychotropic substances". However, this contradicts our findings and the current international study situation, which identifies polypharmacy and, for example, drugs acting on the anticholinergic neurotransmitter system as important causes $[1,7,9,16,23]$. Therefore, drug-related genesis should always be included as a major classification aspect. This is essential to make the medical profession aware of this relationship, especially because of the highly effective preventative capacity confirmed by our IPM and underestimated so far.

In 2019, the adopted future ICD-11 has been approved by the 72nd World Health Assembly and will enter into force in 2022, and hopefully the ICD revision will soon be implemented in Germany. The ICD-11 "6D70.1
Delirium due to psychoactive substances including medication" in its current version will meet the definitional requirements even better and will not only offer medication-related delirium with intoxication or withdrawal state as a subcategory [55]. This differentiated embedding of medications in ICD-11 is clearly more appropriate because it also considers delirium caused by simple drug use and can thus additionally contribute to future prevention. This brings ICD-11 more in line with WHO patient safety efforts, which is also the aim of our study. Corresponding to our clinical expertise, looking more closely at the effects of different opioids on the various human 5-Hydroxytryptamin (5-HT) transporters and the noradrenaline receptors, Rickli et al. have shown, based on the effects of various opioids on the different human 5-HT transporters and the norepinephrine receptors in vitro, that opioids such as tramadol, fentanyl, tapentadol, oxycodone, methadone, and dextromethorphan can induce serotonin syndrome in clinically relevant numbers of patients through their 5-HT transporter or specific $5-\mathrm{HT}_{1 \mathrm{~A}}$ receptor and/or $5-\mathrm{HT}_{2 \mathrm{~A}}$ receptor interactions respectively [56].

From our experience, this can also mimic delirium and should always be clarified by differential diagnosis. As a consequence of our own supportive findings, we have therefore have proposed to the WHO that serotonin syndrome be included as a separate key in the future ICD-11. Awareness raising and continuous sensitization of physicians to iatrogenic drug-induced and preventable causes is the first and most important step to individual active delirium risk minimization, as shown by the results of the IPM intervention. In addition to predominantly CYP2D6 drug interactions in the context of polypharmacy in our patients, it was the cumulative drug effects and ADR on a pharmacodynamic basis and the need for timely dose adjustment in the presence of organ dysfunction that necessitated medication adjustment in the elderly traumatology patient cohort. Our IPM outcome research provides important evidence for the urgent need to assess polypharmacy for drug and patient safety not only in elderly hospitalized patients, but also in older citizens at increasing risk of delirium, cognitive impairment, and even dementia to accelerate underrepresented promising preventative solutions.

\section{Strengths and weaknesses}

The present study is a retrospective study with all its inherent limitations. The patient records and datasets used were not explicitly designed for the study, and data on outcomes and potential confounding variables may be missing. This is equally true for both, the CG and IG. Difficulties to find an appropriate exposed cohort and comparison group in a retrospective cohort study have 
to be considered as well. This is a retrospective clinical controlled study involving two sets of data collection conducted by the same investigators for both. Randomly achieved matched groups with high agreement between CG and IG in age, gender, residency, BMI, most diagnoses, and injury patterns supported better comparison of the two groups. The study clearly determines changes in drug distributions and effectiveness of IPM on outcome with clinically relevant association. The study was not biased by knowledge of outcome status, although outcomes had already occurred at the time of recruitment, because both cohorts included samples blinded to outcome. The large differences within overall incidence of delirium in orthopedic and trauma surgery patients in other studies, ranging from 12 to $51 \%$ (1) are likely related to very different patient settings and to the fact that delirium is a purely clinical diagnosis and hypoactive or mixed subtypes may be underreported as they also may be in our cohorts. The misinterpretation of delirium as dementia or incipient dementia also needs to be discussed as a cause for the wide variation in incidence. Because of the unavailability of delirium screening assessments and because of the retrospective character of the study, we focused only on delirium complicating hospitalization as a robust and most concise manifestation recorded in the hospital discharge letter. Undocumented, less prominent delirium must also be assumed in our cohort. Because the same senior medical professionals were responsible for patient medical care and IPM throughout the observation period, the recording of complicating delirium and associated factors in the database can be considered fairly accurate and consistent. Confounding was minimized by subsequent adjustment for an extremely broad spectrum of variables as potential co-risk factors. The independent positive association obtained thus excluded a wide-ranged potential confounder spectrum. In this regard, this is the first clinical study to document a strong association of IPM with reduced complicating delirium. The study topic addresses an urgent and demographically increasing public health problem, and IPM emerges as a compelling prevention tool that is still underrepresented.

Not all variables that have been shown to have a significant impact on delirium in other studies could be validated in this study. This is probably due to the different power of the studies compared.

We did not include intraoperative parameters such as operation time and blood loss, which would have been of further interest. But regarding the analysis of an extremely broad range of potential delirium-associated factors, another strength is that the most relevant associated variables identified correspond almost entirely to the prognostic risk factors for the manifestation of delirium recorded in the ICD-10.

With the IPM, a continuity of interdisciplinary cooperation has been established in which the patient-oriented optimization of acute treatment in geriatric traumatology is always in the forefront. The continued focus on avoiding drug-induced risks and individually considering drug interactions and overdosages is likely to have had an additional overarching positive systemic class effect over the years.

The compelling pilot data from our retrospective study of IPM efficacy support the feasibility of designing a future prospective study that includes a larger patient population and comprehensive delirium screening.

\section{Conclusions}

IPM with focus on 6 frontline aspects including reduction of antipsychotics, anticholinergic burden, benzodiazepines, serotonergic opioids, elimination of pharmacokinetic and pharmacodynamic drug interactions and overdosage is highly effective in the prevention of complicating delirium in the elderly trauma patients. Because of the far-reaching consequences of delirium and for the overall patient safety efforts, it should be integrated as an essential and mandatory preventative contribution. The identified delirium-associated factors are consistent with those outlined in ICD-10 and several previous studies and may be helpful if integrated into a consecutively improved, more sophisticated screening scale to identify patients at risk. IPM effectively contributes to the current WHO goal of increasing patient safety in polypharmacy by preventing delirium as a serious complication. Because of its wide-ranging practical relevance, including the upstream outpatient setting, bedside teaching of human medicine students in their final practical year was expanded to include prevention of drug-related risks in the older patients as part of this IPM. For earliest prevention, we have also started to conduct cross-sectoral trainings with great resonance on cognitive risks of polypharmacy including delirium with interprofessional workshops in the outpatient setting throughout SaxonyAnhalt, targeting their primary care physicians, nurses, and pharmacists.

\footnotetext{
Abbreviations

ACE inhibitors: Angiotensin converting enzyme inibitors; ADR: Adverse Drug Reactions; AV block: Atrioventricular block; BIS formula: Berlin Initiative Study (BIS) eGFR eqs.; BMI: Body mass index = weight (in kg) / height $\wedge 2\left(\right.$ in $\mathrm{m}^{2}$ ).; CG: Control group; Cl: Confidence interval; CNS disorders: Central nervous system disorders; COPD: Chronic obstructive pulmonary disease; CYP2D6: Cytochrome P450 2D6; CYP3A4: Cytochrome P450 3A4; CYP2C19: Cytochrome P450 2C19; DSM: Diagnostic and Statistical Manual of Mental Disorders of the American Psychiatric Association classification system; ECG: Electrocardiogram; FORTA: Fit fOR The Aged; GFR: Glomerular filtration rate; 5-HT: 5-Hydroxytryptamin; ICD-classification: International Classification of Diseases;
} 
ICU: Intensive care unit; IG: Intervention group; IMC: Intermediate care; IPM: Individual Pharmacotherapy Management; MAl: Medication Appropriateness Index; MCV: Mean corpuscular volume; NSAIDs: Nonsteroidal anti-inflammatory drugs; OR: Odds ratio; Orbis: Hospital information system software; PPI: Proton pump inhibitors; Priscus: Potentially inappropriate medication in the elderly; QT interval: Time from the start of the Q wave to the end of the T wave (measurement on ECG); SD: Standard deviation; Stopp-Start: Screening Tool of Older Persons' Prescriptions - Screening Tool to Alert to Right Treatment; UKH: University Hospital Halle (Saale); WHO: World Health Organization; Würzburger pain drip: Tramadol, metamizole, and metoclopramide.

\section{Acknowledgements}

Dr. Christine Lautenschläger, Institute of Medical Epidemiology, Biostatistics and Informatics, Faculty of Medicine Martin-Luther-University HalleWittenberg, Germany, deserves our sincere thanks for her statistical advice. The authors would like to thank Mrs. Claudia Wölfer, Head of the Nursing Clinic Management, Department of Orthopedics, Trauma and Reconstructive Surgery, and the entire nursing team of the ward for their conscientious and empathetic participation in our ward rounds, precise patient records, and competent and valuable contributions to the success of this established IPM intervention, as well as all participating and performing residents and specialists of the Department of Orthopedics, Trauma and Reconstructive Surgery, Division of Geriatric Traumatology, and attending geriatricians, medical students and the team of the physiotherapists.

\section{Authors' contributions}

UW and RN and KSD designed the study. LD and HG collected the data and LD performed the statistical analysis. UW performed the IPM and RN and UW conducted the ward rounds with medication adjustments. RN and KSD were responsible for the surgical and perioperative patient care. LD and UW interpreted the results and wrote the manuscript. RN and KSD contributed to the manuscript. All authors read and approved the final manuscript.

\section{Authors' information}

RN, head of Division of Geriatric Traumatology, has been the senior physician in charge of geriatric trauma patients since 2008, ensuring continuity and uniformity of care for the patients included in this study. He is the coordinator of the Aging Trauma Center (ATZ), Department of Orthopedics, Trauma and Reconstructive Surgery, Division of Geriatric Traumatology, University Hospital Halle (Saale), Germany. As a member of UW's pharmacotherapy management team, he was awarded the 2020 "Lohfert Preis."

UW is head of Department Pharmacotherapy Management at the University Hospital Halle (Saale) with a focus on polypharmacy in transplantation, intensive care and geriatrics. She has been conducting IPM since 2011 with an expertise of currently $>38,000$ own medication reviews and leads in-clinic and cross-sectoral interprofessional projects. She is an associate member of the Drug Commission of the German Medical Association and a member of national and international Delphi expert panels on polypharmacy and medication in the elderly. In addition to the "Distinguished Educator" certificate of the Academy of the International Transplantation Society, 2014, she received the "Lohfert-Preis" 2020 for measurable innovations to improve patient and drug safety, the "German Medical Award" 2020 for Medical Management, and the "Future Award Healthcare Industry" - "Deutscher Zukunftspreis Gesundheitswirtschaft cdgw 2021".

\section{Funding}

Open Access funding enabled and organized by Projekt DEAL. No grant from any funding agency was received for the conduct of this study and preparation of the manuscript. We acknowledge the financial support of the Open Access Publication Fund of the Martin Luther University Halle-Wittenberg.

\section{Availability of data and materials}

The datasets generated and analysed for the current study are available from the corresponding author on reasonable request.

\section{Declarations}

\section{Ethics approval and consent to participate}

The Ethics Committee of the Medical Faculty of the Martin Luther University Halle-Wittenberg approved that no ethical concerns are raised with regard to the retrospective, anonymized data collection and analysis. Patient interests worthy of protection are not affected by the completely anonymized collection and analysis of the study data, and no further ethical approval is required for this retrospective study from data obtained for clinical purposes from routine care. The Ethics Committee of the Medical Faculty of the Martin Luther University Halle-Wittenberg waived the requirement for informed consent for the entirely anonymized data collection and data analysis of all patients. We confirm that all methods were performed in accordance with the relevant guidelines and regulations, such as the ethical standards of the institutional ethics committee and with the 1964 Helsinki Declaration and its subsequent amendments or comparable ethical standards.

\section{Consent for publication}

\section{Not applicable.}

\section{Competing interests}

$L D, H G, R N$, and KSD declare that they have no competing interests. UW received honoraria for scientific lectures on risks of polypharmacy from Bristol Myers Squibb and Pfizer.

\section{Author details}

${ }^{1}$ Pharmacotherapy Management Department, University Hospital Halle (Saale), Ernst-Grube-Straße 40, 06120 Halle (Saale), Germany. ${ }^{2}$ Internal Medicine Clinic I, Martha Maria Hospital, Halle (Saale), Germany. ${ }^{3}$ Internal Medicine Cardiology and Pulmonology, Asklepios Clinic Wandsbek, Hamburg, Germany. ${ }^{4}$ Department of Orthopedics, Trauma and Reconstructive Surgery, Division of Geriatric Traumatology, University Hospital Halle (Saale), Halle (Saale), Germany. ${ }^{5}$ Department of Orthopedics, Trauma and Reconstructive Surgery, University Hospital Halle (Saale), Halle (Saale), Germany.

Received: 3 July 2021 Accepted: 10 November 2021

Published online: 06 January 2022

\section{References}

1. Inouye SK, Westendorp RG, Saczynski JS. Delirium in elderly people. Lancet. 2014;383(9920):911-22. https://doi.org/10.1016/S01406736(13)60688-1 Epub 2013 Aug 28. PMID: 23992774; PMCID: PMC4120864.

2. Young J, Inouye SK. Delirium in older people. BMJ. 2007;334(7598):842-6. https://doi.org/10.1136/bmj.39169.706574.AD PMID: 17446616; PMCID: PMC1853193.

3. Neufeld KJ, Leoutsakos JM, Sieber FE, Wanamaker BL, Gibson Chambers $\mathrm{JJ}$, Rao V, et al. Outcomes of early delirium diagnosis after general anesthesia in the elderly. Anesth Analg. 2013;117(2):471-8. https://doi.org/ 10.1213/ANE.0b013e3182973650. Epub 2013 June 11. PMID: 23757476; PMCID: PMC4017627.

4. Tropea J, LoGiudice D, Liew D, Gorelik A, Brand C. Poorer outcomes and greater healthcare costs for hospitalised older people with dementia and delirium: a retrospective cohort study. Int J Geriatr Psychiatry. 2017;32(5):539-47. https://doi.org/10.1002/gps.4491 Epub 2016 Apr 25. PMID: 27114271.

5. Fick DM, Steis MR, Waller JL, Inouye SK. Delirium superimposed on dementia is associated with prolonged length of stay and poor outcomes in hospitalized older adults. J Hosp Med. 2013;8(9):500-5. https:// doi.org/10.1002/jhm.2077 Epub 2013 Aug 19. PMID: 23955965; PMCID: PMC3928030.

6. Fox C, Smith T, Maidment I, Chan WY, Bua N, Myint PK, et al. Effect of medications with anti-cholinergic properties on cognitive function, delirium, physical function and mortality: a systematic review. Age Ageing. 2014;43(5):604-15. https://doi.org/10.1093/ageing/afu096 Epub 2014 Jul 19. PMID: 25038833.

7. Alagiakrishnan K, Wiens CA. An approach to drug induced delirium in the elderly. Postgrad Med J. 2004;80(945):388-93. https://doi.org/10.1136/ pgmj.2003.017236 PMID: 15254302; PMCID: PMC1743055.

8. Masnoon N, Shakib S, Kalisch-Ellett L, Caughey GE. What is polypharmacy? A systematic review of definitions. BMC Geriatr. 2017;17(1):230. https://doi.org/10.1186/s12877-017-0621-2 PMID: 29017448; PMCID: PMC5635569. 
9. Francis J, Young, BG. Patient education: Delirium (Beyond the Basics). ed. UpToDate. 2018. https://www.uptodate.com/contents/delirium-beyondthe-basics?view=print. Accessed 28 Jan 2021.

10. Villalba-Moreno AM, Alfaro-Lara ER, Pérez-Guerrero MC, Nieto-Martín MD, Santos-Ramos B. Systematic review on the use of anticholinergic scales in poly pathological patients. Arch Gerontol Geriatr. 2016;62:1-8. https:// doi.org/10.1016/j.archger.2015.10.002 Epub 2015 Oct 14. Erratum in: Arch Gerontol Geriatr. 2016 May-Jun;64:178-80. PMID: 26518612.

11. Shinohara $M$, Yamada M. Drug-induced cognitive impairment. Brain Nerve. 2016;68(4):421-8. https://doi.org/10.11477/mf.1416200415 PMID: 27056860.

12. Mietani K, Sumitani M, Ogata T, Shimojo N, Inoue R, Abe H, et al. Dysfunction of the blood-brain barrier in postoperative delirium patients, referring to the axonal damage biomarker phosphorylated neurofilament heavy subunit. Plos One. 2019;14(10):e0222721. https://doi.org/10.1371/ journal.pone.0222721 PMID: 31574089; PMCID: PMC6771997.

13. Barr J, Fraser GL, Puntillo K, Ely EW, Gélinas C, Dasta JF, et al. Clinical practice guidelines for the management of pain, agitation, and delirium in adult patients in the intensive care unit. Crit Care Med. 2013;41(1):263306. https://doi.org/10.1097/CCM.0b013e3182783b72 PMID: 23269131.

14. de Rooij SE, van Munster BC, Korevaar JC, Levi M. Cytokines and acute phase response in delirium. J Psychosom Res. 2007;62(5):521-5. https:// doi.org/10.1016/j.jpsychores.2006.11.013 PMID: 17467406.

15. Kratz T, Heinrich M, Schlauß E, Diefenbacher A. Preventing postoperative delirium. Dtsch Arztebl Int. 2015;112(17):289-96. https://doi.org/10.3238/ arztebl.2015.0289 PMID: 26008890; PMCID: PMC4452898.

16. Robinson TN, Eiseman B. Postoperative delirium in the elderly: diagnosis and management. Clin Interv Aging. 2008;3(2):351-5. https://doi.org/10 2147/cia.s2759 PMID: 18686756; PMCID: PMC2546478.

17. Lipowski ZJ. Transient cognitive disorders (delirium, acute confusional states) in the elderly. Am J Psychiatry. 1983;140(11):1426-36. https://doi. org/10.1176/ajp.140.11.1426.

18. Grover S, Sharma A, Aggarwal M, Mattoo SK, Chakrabarti S, Malhotra $\mathrm{S}$, et al. Comparison of symptoms of delirium across various motoric subtypes. Psychiatry Clin Neurosci. 2014;68(4):283-91. https://doi.org/10. 1111/pcn.12131 Epub 2013 Dec 25. PMID: 24372977.

19. Santana Santos F, Wahlund LO, Varli F, Tadeu Velasco I, Eriksdotter JM. Incidence, clinical features and subtypes of delirium in elderly patients treated for hip fractures. Dement Geriatr Cogn Disord. 2005;20(4):231-7. https://doi.org/10.1159/000087311.

20. Albrecht JS, Marcantonio ER, Roffey DM, Orwig D, Magaziner J, Terrin M, et al. Functional outcomes in cardiovascular patients undergoing surgical hip fracture repair cognitive ancillary study investigators. Stability of postoperative delirium psychomotor subtypes in individuals with hip fracture. J Am Geriatr Soc. 2015;63(5):970-6. https://doi.org/10.1111/jgs. 13334 Epub 2015 May 4. PMID: 25943948; PMCID: PMC4439362.

21. European Delirium Association; American Delirium Society. The DSM-5 criteria, level of arousal and delirium diagnosis: inclusiveness is safer. BMC Med. 2014;12:141. https://doi.org/10.1186/s12916-014-0141-2 PMID: 25300023; PMCID: PMC4177077.

22. Deutsches Institut für Medizinische Dokumentation und Information (2019): DIMDI - ICD-10-GM Version 2020. https://www.dimdi.de/static/de/ klassifikationen/icd/icd-10-gm/kode-suche/htmlgm2020/block-f00-f09. htm. Accessed 10 Feb 2021.

23. Aloisi G, Marengoni A, Morandi A, Zucchelli A, Cherubini A, Mossello E, et al. Drug prescription and delirium in older inpatients: results from the nationwide multicenter Italian delirium day 2015-2016. J Clin Psychiatry. 2019;80(2):18m12430. https://doi.org/10.4088/JCP.18m12430 PMID: 30901165.

24. Su X, Meng ZT, Wu XH, Cui F, Li HL, Wang DX, et al. Dexmedetomidine for prevention of delirium in elderly patients after non-cardiac surgery: a randomised, double-blind, placebo-controlled trial. Lancet. 2016;388(10054):1893-902. https://doi.org/10.1016/S0140-6736(16) 30580-3 Epub 2016 Aug 16. PMID: 27542303.

25. Meagher DJ, Leonard M, Donnelly S, Conroy M, Adamis D, Trzepacz PT. A longitudinal study of motor subtypes in delirium: relationship with other phenomenology, etiology, medication exposure and prognosis. J Psychosom Res. 2011;71(6):395-403. https://doi.org/10.1016/j.jpsychores. 2011.06.001 Epub 2011 Jul 2. PMID: 22118382.

26. Oh ES, Li M, Fafowora TM, Inouye SK, Chen CH, Rosman LM, et al. Preoperative risk factors for postoperative delirium following hip fracture repair: a systematic review. Int J Geriatr Psychiatry. 2015;30(9):900-10. https:// doi.org/10.1002/gps.4233 Epub 2014 Dec 11. PMID: 25503071; PMCID: PMC4465414.

27. Sanofi-Aventis Deutschland $\mathrm{GmbH}$. Fachinformation Novalgin ${ }^{\circledR} 1$ g-Injektionslösung Novalgin ${ }^{\circledR}$ 2,5 g-Injektionslösung. Sanofi-Aventis Deutschland GmbH. 2021:1-5. https://mein.sanofi.de/produkte/Noval gin/Downloads?id=8410b138-5ca7-4e0d-9f95-ce968b42eddd. Accessed 29 Jan 2021.

28. Stadapharm GmbH. Fachinformation MCP Stada $1 \mathrm{mg} / \mathrm{ml}$ Lösung zum Einnehmen. Stadapharm GmbH. 2020:1-4. http://fachinformation.srz. de/pdf/stadapharm/mcpstada1mgmll\%C3\%B6sungzumeinnehmen.pdf. Accessed 30 Jan 2021.

29. World Health Organization Expert Committee on drug dependence. Critical review report: tramadol: World Health Organization 41st ECDD; 2018. p. 1-51. https://www.who.int/medicines/access/controlled-substances/ Tramadol.pdf. Accessed 16 May 2021

30. AbZ-Pharma GmbH. Fachinformation Tramadol AbZ 50 mg/ml Injektionslösung. AbZ-Pharma GmbH. 2018.,version 2:1-10. https://s3.eu-central-1. amazonaws.com/prod-cerebro-ifap/media_all/84450.pdf. Accessed 16 May 2021.

31. Ingelman-Sundberg M. Genetic polymorphisms of cytochrome P450 2D6 (CYP2D6): clinical consequences, evolutionary aspects and functional diversity. Pharmacogenomics J. 2005;5(1):6-13. https://doi.org/10.1038/sj. tpj.6500285 PMID: 15492763.

32. Zhou SF. Polymorphism of human cytochrome P450 2D6 and its clinical significance: part II. Clin Pharmacokinet. 2009;48(12):761-804. https://doi. org/10.2165/11318070-000000000-00000 PMID: 19902987.

33. Aliud Pharma GmbH. Fachinformation Tilidin AL comp. Retardtabletten. Aliud Pharma GmbH. 2020:1-4. http://fachinformation.srz.de/pdf/aliud pharma/tilidinalcompretardtabletten.pdf. Accessed 28 Jan 2021.

34. Mundipharma GmbH. Fachinformation (SPC) Palladon $1,3 \mathrm{mg} / 2,6 \mathrm{mg}$ Hartkapseln: Mundipharma GmbH; 2017. p. 1-3. https://s3.eu-central-1. amazonaws.com/prod-cerebro-ifap/media_all/78970.pdf. Accessed 29 Jan 2021

35. Juliebø V, Bjøro K, Krogseth M, Skovlund E, Ranhoff AH, Wyller TB. Risk factors for preoperative and postoperative delirium in elderly patients with hip fracture. J Am Geriatr Soc. 2009;57(8):1354-61. https://doi.org/ 10.1111/j.1532-5415.2009.02377.x Epub 2009 Jul 2. PMID: 19573218.

36. Raats JW, van Eijsden WA, Crolla RM, Steyerberg EW, van der Laan L. Risk factors and outcomes for postoperative delirium after major surgery in elderly patients. Plos One. 2015;10(8):e0136071. https://doi.org/10.1371/ journal.pone.0136071 PMID: 26291459; PMCID: PMC4546338.

37. Myint PK, Owen S, McCarthy K, Pearce L, Moug SJ, Stechman MJ, et al. Is anemia associated with cognitive impairment and delirium among older acute surgical patients? Geriatr Gerontol Int. 2018;18(7):1025-30. https:// doi.org/10.1111/ggi.13293 Epub 2018 Mar 1. PMID: 29498179; PMCID: PMC6099313.

38. Kolanowski A, Mogle J, Fick DM, Campbell N, Hill N, Mulhall P, et al. Anticholinergic exposure during rehabilitation: cognitive and physical function outcomes in patients with delirium superimposed on dementia. Am J Geriatr Psychiatry. 2015;23(12):1250-8. https://doi.org/10.1016/j. jagp.2015.07.004

39. Beard JR, Officer A, de Carvalho IA, Sadana R, Pot AM, Michel JP, et al. The world report on ageing and health: a policy framework for healthy ageing. Lancet. 2016:387(10033):2145-54. https://doi.org/10.1016/ S0140-6736(15)00516-4 Epub 2015 Oct 29. PMID: 26520231; PMCID: PMC4848186.

40. Saravana-Bawan B, Warkentin LM, Rucker D, Carr F, Churchill TA, Khadaroo RG. Incidence and predictors of postoperative delirium in the older acute care surgery population: a prospective study. Can J Surg. 2019;62(1):33-8. https://doi.org/10.1503/cjs.016817 PMID: 30693744; PMCID: PMC6351261.

41. Zhang X, Tong DK, Ji F, Duan XZ, Liu PZ, Qin S, et al. Predictive nomogram for postoperative delirium in elderly patients with a hip fracture. Injury. 2019;50(2):392-7. https://doi.org/10.1016/j.injury.2018.10.034.

42. Galyfos GC, Geropapas GE, Sianou A, Sigala F, Filis K. Risk factors for postoperative delirium in patients undergoing vascular surgery. J Vasc Surg. 2017;66(3):937-46. https://doi.org/10.1016/j.jvs.2017.03.439 Epub 2017 Jun 2. PMID: 28583731

43. Wesselink EM, Kappen TH, van Klei WA, Dieleman JM, van Dijk D, Slooter AJ. Intraoperative hypotension and delirium after on-pump cardiac 
surgery. Br J Anaesth. 2015;1 15(3):427-33. https://doi.org/10.1093/bja/ aev256 Epub 2015 Jul 25. PMID: 26209856; PMCID: PMC4635646.

44. Hirsch J, DePalma G, Tsai TT, Sands LP, Leung JM. Impact of intraoperative hypotension and blood pressure fluctuations on early postoperative delirium after non-cardiac surgery. Br J Anaesth. 2015;115(3):418-26. https://doi.org/10.1093/bja/aeu458 Epub 2015 Jan 23. PMID: 25616677; PMCID: PMC4533731.

45. Nguyen DN, Huyghens L, Parra J, Schiettecatte J, Smitz J, Vincent JL. Hypotension and a positive fluid balance are associated with delirium in patients with shock. Plos One. 2018;13(8):e0200495. https://doi.org/10. 1371/journal.pone.0200495 PMID: 30086136; PMCID: PMC6080753.

46. Wang LH, Xu DJ, Wei XJ, Chang HT, Xu GH. Electrolyte disorders and aging: risk factors for delirium in patients undergoing orthopedic surgeries. BMC Psychiatry. 2016;16(1):418. https://doi.org/10.1186/s12888-0161130-0 PMID: 27881118; PMCID: PMC5120472.

47. Ruggiero C, Bonamassa L, Pelini L, Prioletta I, Cianferotti L, Metozzi A, et al. Early post-surgical cognitive dysfunction is a risk factor for mortality among hip fracture hospitalized older persons. Osteoporos Int. 2017;28:667-75. https://doi.org/10.1007/s00198-016-3784-3.

48. Brouquet A, Cudennec T, Benoist S, Moulias S, Beauchet A, Penna C, et al. Impaired mobility, ASA status and administration of tramadol are risk factors for postoperative delirium in patients aged 75 years or more after major abdominal surgery. Ann Surg. 2010;251(4):759-65. https://doi.org/ 10.1097/SLA.0b013e3181c1cfc9 PMID: 20224380.

49. Woodhouse R, Burton JK, Rana N, Pang YL, Lister JE, Siddiqi N. Interventions for preventing delirium in older people in institutional long-term care. Cochrane Database Syst Rev. 2019;4(4):CD009537. https://doi. org/10.1002/14651858.CD009537.pub3 PMID: 31012953; PMCID: PMC6478111

50. Hein C, Forgues A, Piau A, Sommet A, Vellas B, Nourhashémi F. Impact of polypharmacy on occurrence of delirium in elderly emergency patients. J Am Med Dir Assoc. 2014;15(11):850.e11-5. https://doi.org/10.1016/j. jamda.2014.08.012 PMID: 25405712.

51. an Velthuijsen EL, Zwakhalen SMG, Pijpers E, van de Ven LI, Ambergen T, Mulder WJ, et al. Effects of a medication review on delirium in older hospitalised patients: a comparative retrospective cohort study. Drugs Aging. 2018;35(2):153-61. https://doi.org/10.1007/s40266-018-0523-9 PMID: 29396715; PMCID: PMC5847150.

52. American Geriatrics Society Expert Panel on Postoperative Delirium in Older Adults. Postoperative delirium in older adults: best practice statement from the American Geriatrics Society. J Am Coll Surg. 2015;220(2):136-48.e1. https://doi.org/10.1016/j.jamcollsurg.2014.10.019 Epub 2014 Nov 14. PMID: 25535170.

53. Fick DM, Semla TP. 2012 American Geriatrics Society beers criteria: new year, new criteria, new perspective. J Am Geriatr Soc. 2012;60(4):614-5. https://doi.org/10.1111/j.1532-5415.2012.03922.x Epub 2012 Feb 29. PMID: 22376003.

54. Wilson JE, Mart MF, Cunningham C, Shehabi Y, Girard TD, MacLullich AMJ, et al. Delirium. Nat Rev Dis Primers. 2020;6(1):90. https://doi.org/10.1038/ s41572-020-00223-4 Erratum in: Nat Rev Dis Primers. 2020 Dec 1;6(1):94. PMID: 33184265.

55. World Health Organization. ICD-11 for Mortality and Morbidity Statistics (ICD-11 MMS), version for preparing implementation: World Health Organization; 2021. https://icd.who.int/dev11/l-m/en. Accessed 12 Jun 2021.

56. Rickli A, Liakoni E, Hoener MC, Liechti ME. Opioid-induced inhibition of the human 5-HT and noradrenaline transporters in vitro: link to clinical reports of serotonin syndrome. Br J Pharmacol. 2018;175(3):532-43. https://doi.org/10.1111/bph.14105 Epub 2018 Jan 6. PMID: 29210063; PMCID: PMC5773950.

\section{Publisher's Note}

Springer Nature remains neutral with regard to jurisdictional claims in published maps and institutional affiliations.
Ready to submit your research? Choose BMC and benefit from:

- fast, convenient online submission

- thorough peer review by experienced researchers in your field

- rapid publication on acceptance

- support for research data, including large and complex data types

- gold Open Access which fosters wider collaboration and increased citations

- maximum visibility for your research: over $100 \mathrm{M}$ website views per year

At BMC, research is always in progress.

Learn more biomedcentral.com/submissions 